\title{
Controlling Corrosion Resistance of a Biodegradable Mg-Y-Zn Alloy with LPSO Phases via Multi-pass ECAP Process
}

\author{
Li-Sha Wang ${ }^{1,2} \cdot$ Jing-Hua Jiang $^{1} \cdot$ Bassiouny Saleh ${ }^{1,3} \cdot$ Qiu-Yuan Xie $^{1} \cdot$ Qiong Xu $^{1} \cdot$ Huan Liu ${ }^{1} \cdot$ Ai-Bin Ma ${ }^{1,2}$
}

Received: 6 December 2019 / Revised: 29 January 2020 / Published online: 16 April 2020

(c) The Chinese Society for Metals (CSM) and Springer-Verlag GmbH Germany, part of Springer Nature 2020

\begin{abstract}
$\mathrm{Mg}-\mathrm{RE}$ (rear earth) alloys with long period stacking (LPSO) structures have great potential in biomedical applications. The present work focused on the microstructure and corrosion behaviors of $\mathrm{Mg}_{98.5} \mathrm{Y}_{1} \mathrm{Zn}_{0.5}$ alloys with 18R LPSO structure after equal channel angular pressing (ECAP). The results showed that the ECAP process changed the grain size and the distribution of LPSO particles thus controlled the total corrosion rates of $\mathrm{Mg}_{98.5} \mathrm{Y}_{1} \mathrm{Zn}_{0.5}$ alloys. During the ECAP process from 0p to $12 p$, the grain size reduced from $160-180 \mu \mathrm{m}$ (as-cast) to 6-8 $\mu \mathrm{m}$ (12p). The LPSO structures became kinked (4p), then started to be broken into smaller pieces (8p), and at last comminuted to fine particles and redistributed uniformly inside the matrix (12p). The improvement in the corrosion resistance for ECAP samples was obtained from $0 \mathrm{p}$ to $8 \mathrm{p}$, with the corrosion rate reduced from $3.24 \mathrm{~mm} /$ year (0p) to $2.35 \mathrm{~mm} /$ year (8p) in simulated body fluid, and the 12p ECAP alloy exhibited the highest corrosion rate of $4.54 \mathrm{~mm} /$ year.
\end{abstract}

Keywords Corrosion behavior $\cdot$ Long period stacking ordered phase $\cdot$ Magnesium alloys $\cdot$ Equal channel angular pressing (ECAP) process $\cdot$ Biomaterials

\section{Introduction}

Owing to their relatively high mechanical properties and good biocompatibility, Mg-RE (rear earth) alloys with long period stacking (LPSO) structures have been considered as one of the most promising magnesium alloys with enormous potential in biomedical applications [1-13]. The yield strength and elongation of a rapid solidified metallurgy $\mathrm{Mg}_{97} \mathrm{Y}_{2} \mathrm{Zn}_{1}$ alloy could exceed $600 \mathrm{MPa}$ and 5\%, respectively [14]. The excellent mechanical performance was mainly attributed to the fine $\alpha-\mathrm{Mg}$ grains and precipitation of novel LPSO structures inside the grains [8-10, 15, 16]. In

Available online at https://link.springer.com/journal/40195.

Jing-Hua Jiang

jinghua-jiang@hhu.edu.cn

$\triangle$ Huan Liu

liuhuanseu@hhu.edu.cn

1 College of Mechanics and Materials, Hohai University, Nanjing 210098, China

2 Suqian Institute, Hohai University, Suqian 223800, China

3 Production Engineering Department, Alexandria University, Alexandria 21544, Egypt addition, the absence of toxic elements such as $\mathrm{Al}$ in these alloys could significantly reduce the risk of damage to the human body caused by implants $[17,18]$. However, limitations such as poor corrosion resistances with high evolutions of hydrogen $\left(\mathrm{H}_{2}\right)$ gas and uncontrollable degradation rates remain to be solved before their long-term application as biomedical implants. Therefore, it is of great significance to take measures to improve the corrosion resistance of $\mathrm{Mg}-\mathrm{RE}$ alloy with LPSO structure and further assess their corrosion status in vivo conditions.

Microstructural modification is an interesting approach to alter the corrosion rates of $\mathrm{Mg}$ alloys. It was reported that plastic deformation could improve the corrosion resistance of $\mathrm{Mg}$ alloys through microstructure refinement [19-21]. Gui et al. [20] found that the corrosion resistance of a hot extruded $\mathrm{Mg}-\mathrm{Gd}-\mathrm{Zn}-\mathrm{Zr}-\mathrm{Mn}$ alloy was enhanced with a corrosion rate less than $0.5 \mathrm{~mm} /$ year after immersing in Hank's solution at $37{ }^{\circ} \mathrm{C}$ for $240 \mathrm{~h}$. Wang et al. [22] also reported a decline in corrosion rate of hot-rolled AZ31 alloys in Hank's solution. The improvement in the corrosion resistance was mainly attributed to the severe plastic deformation (SPD)-induced grain refinement. So far, SPD methods such as equal channel angular pressing (ECAP) have already been imposed to $\mathrm{Mg}$ alloys, which could result in refinement of 
microstructure, increment of solid solubility, and elimination of composition segregation [11, 15, 23-29]. These changes in microstructure have significant influences on the corrosion behaviors [30-35]. Unfortunately, the effect of ECAP process on the corrosion properties of $\mathrm{Mg}$ alloys containing LPSO phase remains unrevealed and needs further systematic and in-depth researches. Therefore, we prepared a low-alloying $\mathrm{Mg}_{98.5} \mathrm{Y}_{1} \mathrm{Zn}_{0.5}$ (at\%) alloy containing LPSO phases in this study and employed multi-pass ECAP on it to modify its microstructure. By charactering the corrosion behaviors of ECAP alloys in the simulated body fluid (SBF), we mainly discussed the effects of ECAP numbers on the microstructural evolutions and corrosion mechanisms of fine-grained LPSO-containing Mg alloys.

\section{Experimental}

\subsection{Material and ECAP Processing}

In consideration of proper LPSO content and ease of application in biomedical fields, the material chosen for this research was a low-alloyed $\mathrm{Mg}_{98.5} \mathrm{Y}_{1} \mathrm{Zn}_{0.5}$ (at\%) alloy. The cast alloy was prepared through conventional melting method. Samples were ECAP at $380^{\circ} \mathrm{C}$ with the initial dimensions of $20 \mathrm{~mm} \times 20 \mathrm{~mm} \times 40 \mathrm{~mm}$. Figure $1 \mathrm{a}$, $\mathrm{b}$ illustrates the scheme for the designed ECAP mold and processing route. In ECAP mold, the angle $(\varphi)$ between the horizontal channel and the vertical channel at the intersection was $90^{\circ}$, and the angle $(\psi)$ between the external angles was $0^{\circ}$. An electric furnace was set outside to heat the die evenly. All ECAP processing experiments were performed at $380^{\circ} \mathrm{C}$. Graphite emulsion was used as a lubricant to reduce the friction between the die and the specimens.

\subsection{Microstructural Characterization}

After various passes of ECAP processing, the samples for microstructure observations were machined from ECAP specimens with dimensions of $10 \mathrm{~mm} \times 10 \mathrm{~mm} \times 2 \mathrm{~mm}$. An optical microscopy (OM, Olympus BHM) was used to characterize the microstructure of the as-cast and the ECAP $\mathrm{Mg}_{98.5} \mathrm{Y}_{1} \mathrm{Zn}_{0.5}$ alloys. Samples were mechanically grinded by SiC papers (from 120 to 2000 git), polished by $1-\mu \mathrm{m}$-sized diamond powders, and then etched by the alcohol solution with a volume fraction of $4 \%$ nitric acid. In order to identify various structures of deformed specimens, transmission electron microscope (TEM) analyses were conducted using a FEI Tecnai-G2 TEM at an accelerating voltage of $200 \mathrm{kV}$. The TEM specimen slices were cut perpendicularly to the ECAP direction, mechanically grinded to a thicknessless than $100 \mu \mathrm{m}$, and eventually thinned with the polishing twin-jet electroprocess. The Image J software was used to compute the average grain size of $\mathrm{Mg}_{98.5} \mathrm{Y}_{1} \mathrm{Zn}_{0.5}$ alloys before and after ECAP processing.

\subsection{Examination of corrosion damage and electrochemical responds}

In the current work, the hydrogen evolution tests and electrochemical analyses were carried out to examine the corrosion behaviors of as-cast and ECAP alloys. SBF was employed to conduct the hydrogen evolution test at $37 \pm 0.5^{\circ} \mathrm{C}$ in water bath. Table 1 describes the chemical composition of the used $\mathrm{SBF}$ solution. To maintain the stable $\mathrm{pH}$ value of the corrosive media, the SBF solution was renewed every $24 \mathrm{~h}$. The $\mathrm{CrO}_{3}$ solution $(200 \mathrm{~g} / \mathrm{L})$ was used to clean the corrosion surface after immersion. The corrosion rate was calculated by using both (a)

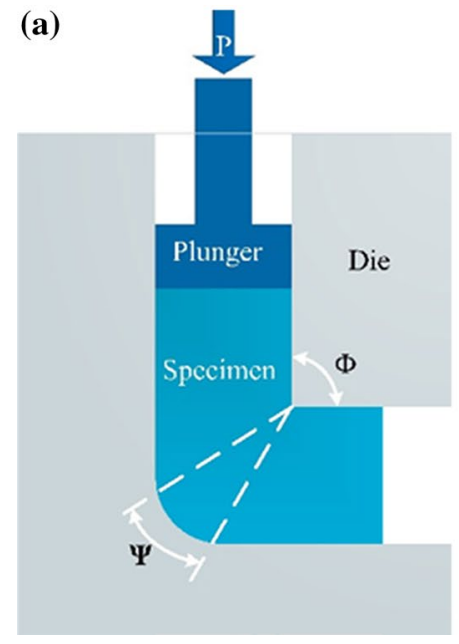

(b)

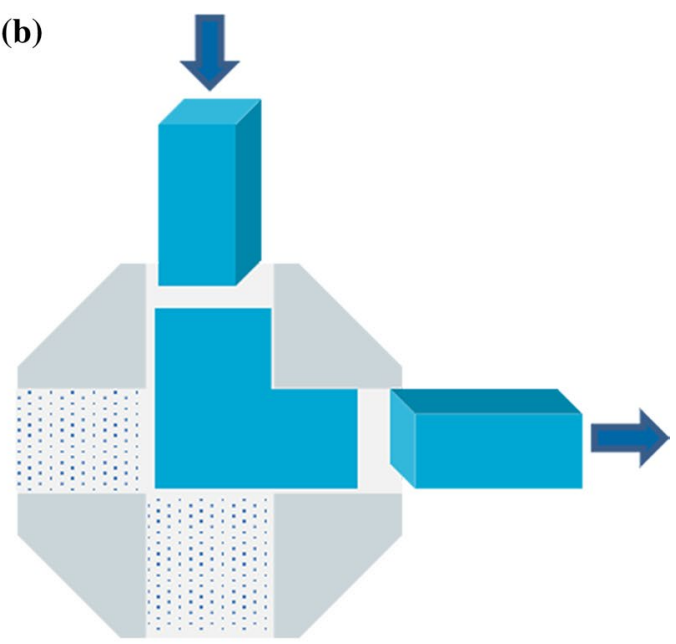

Fig. 1 a Schematic illustration of a typical ECAP (equal channel angular pressing) facility die [27] and b processing route 
Table1 Composition of the simulated body fluid used in this study

\begin{tabular}{ll}
\hline Component & $\begin{array}{l}\text { Concentra- } \\
\text { tion }(\mathrm{g} / \mathrm{L})\end{array}$ \\
\hline $\mathrm{NaCl}$ & 8.0 \\
$\mathrm{CaCl}$ & \\
$\mathrm{KCl}$ & 0.14 \\
$\mathrm{NaHCO}$ & 0.4 \\
$\mathrm{MgCl}_{2} \cdot 6 \mathrm{H}_{2} \mathrm{O}$ & 0.35 \\
$\mathrm{Glucose}$ & 0.1 \\
$\mathrm{NaHPO}_{4} \cdot 2 \mathrm{H}_{2} \mathrm{O}$ & 0.06 \\
$\mathrm{KH}_{2} \mathrm{PO}_{4}$ & 0.06 \\
$\mathrm{MgSO}_{4} \cdot 7 \mathrm{H}_{2} \mathrm{O}$ & 0.06 \\
\hline
\end{tabular}

weight loss and hydrogen immersion approaches. The corrosion rate from weight loss $P_{\mathrm{w}}$ (mm/year) was get via Eq. (1) [36-39]:

$P_{\mathrm{w}}=2.10 \frac{\Delta W}{A t}$,

where $\Delta W(\mathrm{mg})$ is the weight loss of specimen during the immersion, $A\left(\mathrm{~cm}^{2}\right)$ is the exposed surface area, and $t$ (day) is the immersion time [11,36]. And the corrosion rate $P_{\mathrm{AH}}$ ( $\mathrm{mm} / \mathrm{year}$ ) obtained by average hydrogen immersion can be determined via Eq. (2):

$P_{\mathrm{AH}}=2.006 \frac{\Delta V}{A t}$,

where $\Delta V$ is total volume of hydrogen evolved for the total immersion time, $A\left(\mathrm{~cm}^{2}\right)$ is the exposed surface area, and $t$ (day) is the immersion time.

After removing the corrosion products, the surface morphologies of the eroded alloys were characterized by a scanning electron microscope (SEM, Sirion). In addition, a typical three-electrode method was used to differentiate the electrochemical response as a function of processing. The electrochemical experiments were performed on a workstation (CHI660C) with Pt as the counter electrode, saturated calomel electrode (SCE) as the reference electrode, and specimen as the working electrode. The potential range for polarization curves was changed from $-200 \mathrm{mV}_{\mathrm{SCE}}$ to $+500 \mathrm{mV}_{\mathrm{SCE}}$ versus open circuit potential (OCP) with a scan rate of $1 \mathrm{mV} / \mathrm{s}$. Three specimens were measured for each alloy stage to ensure the reproductivity. The instantaneous corrosion rate, $P_{\mathrm{i}}(\mathrm{mm} /$ year), was determined from the corrosion current density $i_{\text {corr }}$ $\left(\mathrm{mA} \mathrm{cm}{ }^{2}\right)$ by Eq. (3) $[19,40]$ :

$P_{i}=22.85 i_{\text {corr }}$.

\section{Results and Discussion}

\subsection{Microstructure Evolution}

Figure 2 shows the microstructure of as-cast and ECAPprocessed $\mathrm{Mg}_{98.5} \mathrm{Y}_{1} \mathrm{Zn}_{0.5}$ alloys with different ECAP passes observed by OM and SEM, which presents the changes in grain size, distribution, and morphology of the LPSO phase. The primary microstructure of as-cast $\mathrm{Mg}_{98.5} \mathrm{Y}_{1} \mathrm{Zn}_{0.5}$ alloy (Fig. 2a, b) consists of large $\alpha-\mathrm{Mg}$ grains and quasi-continuous second phase networks at grain boundaries. The secondary phase was identified as Y/Zn-enriched region with a 18R LPSO structure [11]. The average grain size of as-cast alloy ranges roughly from 160 to $180 \mu \mathrm{m}$ as shown in Fig. 3a. ECAP processing modified the microstructure by deforming and breaking the LPSO precipitations with the increase in total strain. After multipass ECAP, the microstructure of the alloy was efficiently refined through ECAP-induced dynamic recrystallization (DRX) and extreme severe shear deformation (Fig. 2c-h) [41]. The blocky 18R structure became kinked (marked by white circles in Fig. 2d) and surrounded by small recrystallized grains (marked by yellow circles in Fig. 2d) after $4 p$ of ECAP, and there is no obvious broken 18R LPSO phase in $4 p$ ECAP samples. The average grain size of $4 p$ ECAP process alloy was $18-22 \mu \mathrm{m}$ (Fig. $3 \mathrm{~b}$ ). The recrystallization of new grains along the distorted 18R structures shows the evidence of DRX. After eight passes of ECAP, the degree of DRX deepened with the average grain size at about 11-4 $\mu \mathrm{m}$ (Figs. 2e, f, 3c). Moreover, the kinked $18 \mathrm{R}$ structures started to be broken into smaller pieces as a result of the large strain ratio and severe deformation, and the broken 18R structures were marked by white circles. By prolonging ECAP process to $12 \mathrm{p}$, the average grain size of the target alloys was reduced to $6-8 \mu \mathrm{m}$ (Fig. 3d). Furthermore, the distorted $18 \mathrm{R}$ phases completely turned into fine particles and redistributed uniformly within the matrix (Fig. 2g, h).

Figure 4 shows the TEM images of second phases and DRX grains in deformed alloys. As can be seen from Fig. 4a, the as-cast alloy possesses a typical two-phase microstructure with $\alpha-\mathrm{Mg}$ matrix and fine stripe-shaped 18R LPSO structures. It is evident from Fig. $4 \mathrm{~b}$ that the kinking of $18 \mathrm{R}$ phases was easily observed in the $4 \mathrm{p}$ ECAP alloy, which is consistent with reported microstructures in relevant researches that $18 \mathrm{R}$ exhibits good plasticity [8, 42]. Figure $4 c$ displays the existence of the DRX grains in $8 p$ ECAP alloy with a preorientation relationship with 



Fig. 2 Microstructure of as-cast and $\mathrm{Mg}_{98.5} \mathrm{Y}_{1} \mathrm{Zn}_{0.5}$ alloys revealed by OM and SEM: a, c, e, $\mathbf{g}$ OM observation for 0p, 4p, 8p, and 12p; b, d, f, h SEM images for $0 p, 4 p, 8 p$, and $12 p$, respectively

18R structure. Seen from Fig. 4d, a very fine size of $\alpha-\mathrm{Mg}$ grains was observed in 12p ECAP alloy, which is in good agreement with the OM and SEM images of Fig. $2 \mathrm{~g}$, h. Moreover, the presence of the LPSO structure with a diameter of approximately $500 \mathrm{~nm}$ is noticed at grain boundaries. Hagihara et al. [41] investigated the microstructure of extruded $\mathrm{Mg}_{97} \mathrm{Y}_{2} \mathrm{Zn}_{1}$ alloy and elucidated a particle stimulated nucleation mechanism that was related to the accelerated grain refinement around LPSO phase. According to their study, the inconsistency between the deformation of $\alpha-\mathrm{Mg}$ phase and LPSO structures throughout the process could result in the formation of concentrated extreme deformation zones near the $\alpha-\mathrm{Mg} / \mathrm{LPSO}$ interfaces, contributing to the formation of fine DRX grains. 

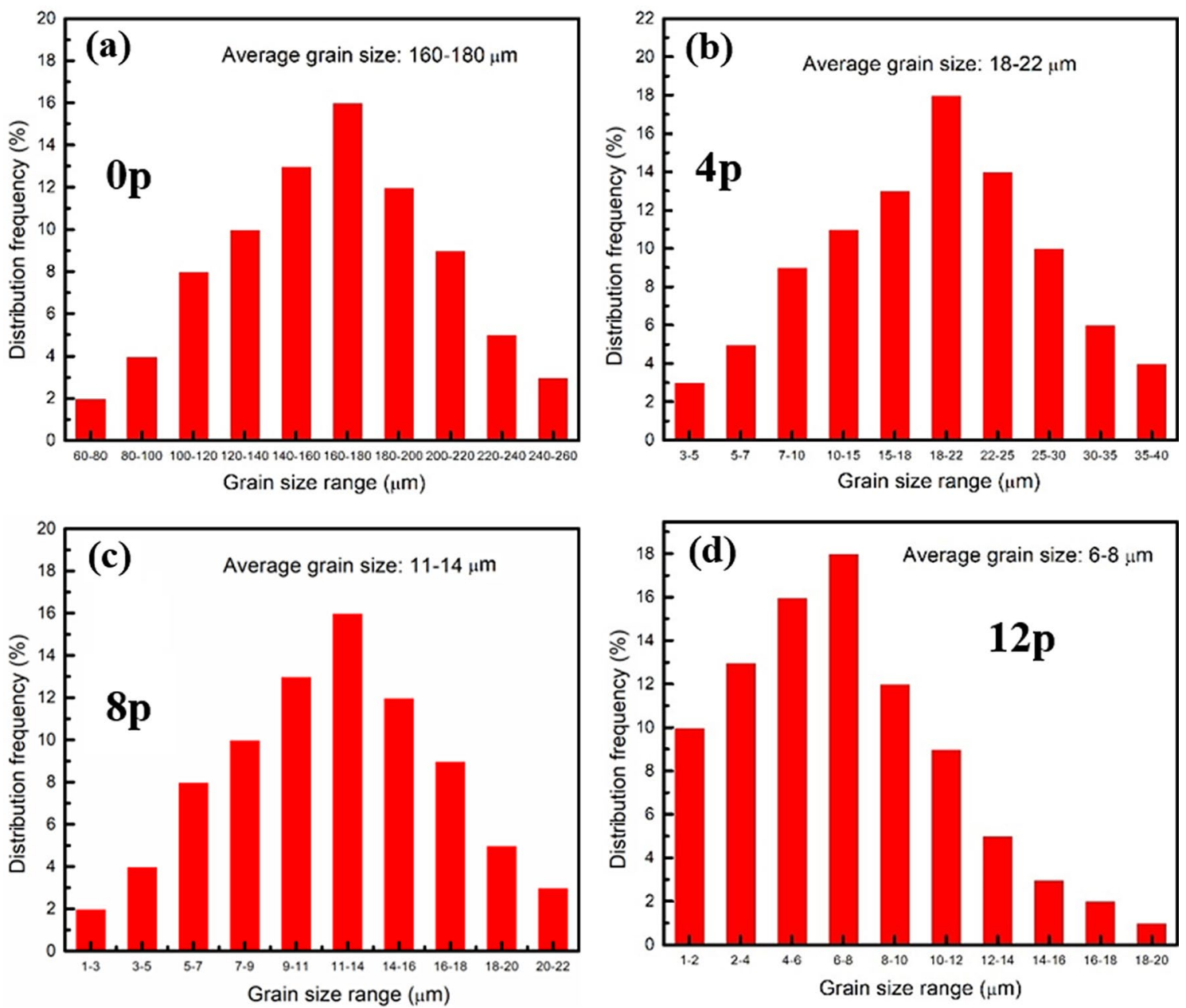

Fig. 3 Histograms of grain size of the $\mathrm{Mg}_{98.5} \mathrm{Y}_{1} \mathrm{Zn}_{0.5}$ alloy after $0,4,8$, and 12 ECAP passes

\subsection{Corrosion Rate}

Figure 5 a shows the results of the hydrogen evolution tests of $\mathrm{Mg}_{98.5} \mathrm{Y}_{1} \mathrm{Zn}_{0.5}$ alloys in as-cast and ECAP conditions immersed in SBF solution at $37 \pm 0.2{ }^{\circ} \mathrm{C}$ for $144 \mathrm{~h}$. During the early $30 \mathrm{~h}$ immersion, the hydrogen evolution rates of the four samples were very slow. Similar hydrogen evolution rates were shown for as-cast and $4 p$ ECAP-processed samples, and they were a bit lower than that of the $8 p$ and $12 p$ ECAP samples. The higher hydrogen release rate for $8 p$ and $12 p$ samples may be related to the surface conditions. The broken LPSO particle inside the 8p and 12p ECAP-processed samples increased the cathodic sites, thus facilitated the hydrogen evolution in the early stage of immersion, making the overall hydrogen evolution amount higher than that of as-cast and 4p ECAP-processed counterparts. Compared with the 8p ECAP-processed specimen, the microstructure of $12 p$-processed samples is fully refined, and it is easier for the redox reaction to take place to form the surface film, thus restraining the hydrogen release to a certain extent for short immersion. Long-time immersion deduces the protective effect, which was evidenced for the increased hydrogen evolution rate for $12 \mathrm{p}$-processed samples after $30 \mathrm{~h}$ immersion, and that may be related to the existence of small LPSO particles. The amount of hydrogen evolution of $12 p$ ECAP sample exceeded that of the as-cast sample after $80 \mathrm{~h}$ immersion and maintained at this level in the following process. After $140 \mathrm{~h}$ immersion, hydrogen evolution rate of the four materials is ranked as $12 p>$ as-cast $>4 p>8 p$. Figure $5 b$ indicates the corrosion rates $(\mathrm{mm} / \mathrm{y})$ of the investigated alloys immersed in SBF solution at $37 \pm 0.2{ }^{\circ} \mathrm{C}$ for $144 \mathrm{~h}$, which were calculated by both average hydrogen evolution rate and weight loss based on Eqs. (1) and (2). The results showed similar trends in corrosion rates of two calculation methods. For all the samples, the corrosion rate calculated by the average hydrogen evolution method $P_{\mathrm{AH}}$ is smaller than that calculated by weight loss method $P_{\mathrm{W}}$, which may be ascribed to the dissolved hydrogen in the $\mathrm{Mg}$ metal and the solution $[37,39,43]$. The 12p ECAP alloy corroded fastest with the highest corrosion rate of $P_{\mathrm{W}} 4.54 \mathrm{~mm} / \mathrm{year}$, sequenced by 

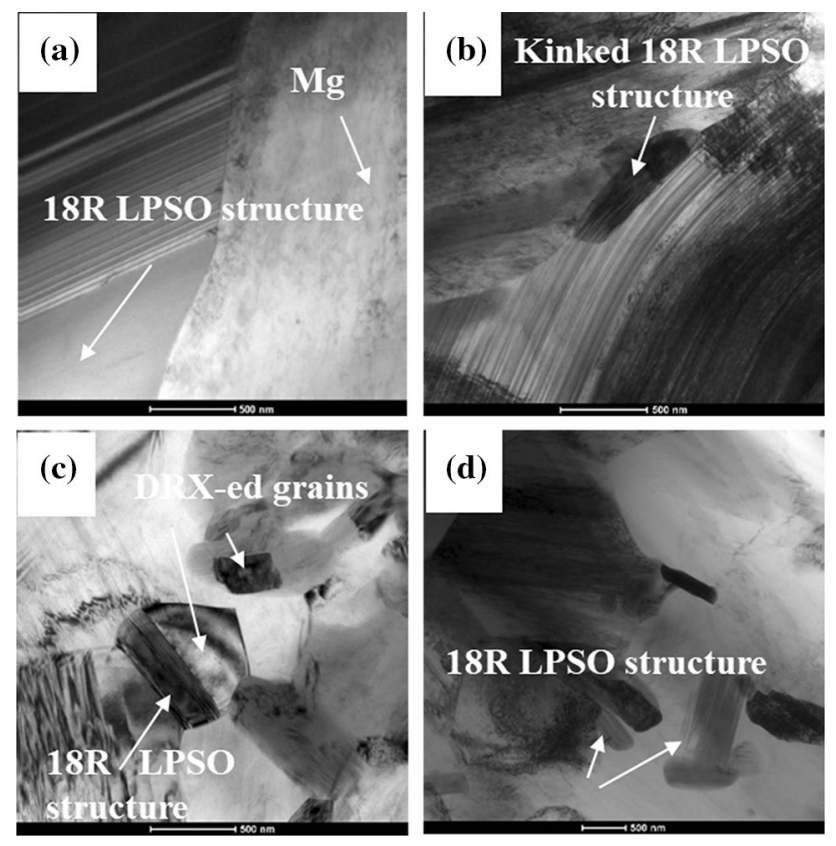

Fig. 4 TEM images of the as-cast and ECAP $\mathrm{Mg}_{98.5} \mathrm{Y}_{1} \mathrm{Zn}_{0.5}$ alloys: $\mathbf{a}$ as-cast; $\mathbf{b} 4 \mathrm{p} ; \mathbf{c} 8 \mathrm{p}$; and $\mathbf{d} 12 \mathrm{p}$

the as-cast samples $P_{\mathrm{W}} 3.24 \mathrm{~mm} /$ year. The corrosion rate of the 8p ECAP alloy was the lowest with $P_{\mathrm{W}} 2.35 \mathrm{~mm} / \mathrm{year}$, suggesting relatively high corrosion resistance in this study.

\subsection{Electrochemical Responds as a Function of Processing}

Figure 6 displays the potentiodynamic polarization (PDP) curves for unprocessed and ECAP $\mathrm{Mg}_{98.5} \mathrm{Y}_{1} \mathrm{Zn}_{0.5}$ alloys. Table 2 summarizes the detailed electrochemical parameters calculated from PDP plots. In general, the corrosion potentials $E_{\text {corr }}$ of ECAP-processed samples are nobler than that of the cast alloy. The 12p-processed specimen has the highest $E_{\text {corr }}$ of $-1.406 \mathrm{~V}_{\mathrm{SCE}}$, while the as-cast alloy possesses the lowest $E_{\text {corr }}$ of $-1.59 \mathrm{~V}_{\mathrm{SCE}}$. With the comparison off our PDP curves, it is possible to find that the ECAP processing led to changes in both anodic and cathodic branches. From the cathode polarization branches, the current densities of the four samples were found to be different: The 12p ECAP alloy exhibits the highest corrosion current density of $25.7 \mu \mathrm{A} \mathrm{cm} \mathrm{cm}^{2}$, while the 8p ECAP sample shows the lowest corrosion current density $\left(4.16 \mu \mathrm{A} \mathrm{cm}{ }^{2}\right)$, followed by the $4 \mathrm{p}$ ECAP sample $\left(6.2 \mu \mathrm{A} \mathrm{cm}{ }^{2}\right)$, which were approximately $80 \%$ and $71 \%$ lower than that of the cast one $\left(21.4 \mu \mathrm{A} \mathrm{cm}^{2}\right)$, respectively. During anodic polarization, the $4 \mathrm{p}$ - and $12 \mathrm{p}$-processed specimens present active dissolution rates, while the as-cast and $8 \mathrm{p}$-processed samples possess a well-defined pitting potential. Typically, the dissolution of $\mathrm{Mg}$ alloy in solutions is always accompanied by hydrogen evolution. As reviewed by several studies, the hydrogen evolution continues at a high rate during the anodic polarization, leading to the accelerations of Mg dissolution [44-46]. Frankel et al. [47] suggested that there is an enhanced catalytic activity in the process of anode polarization. Birbilis et al. [48] have shown that the anodic dissolution process of $\mathrm{Mg}$ alloys includes the formation of protective surface film and the accumulation of noble metal components on the dissolved surface. The noble metal components accelerate the dissolution process [48]. In the present work, the ECAP process from $0 p$ to $12 p$ modified the microstructure of $\mathrm{Mg}-\mathrm{Y}-\mathrm{Zn}$ alloys by refined grains and redistribution of LPSO particles. High grain refinement leads to easy surface film formation through redox reaction which shifted the corrosion potential to the nobler direction. The obvious pitting potential in 8p-processed samples is also the evidence of the protective film (Fig. 6). The rapid dissolution rate shown in 4p-processed samples may be related to the less uniform passive layer formed on the 4 p-processed samples
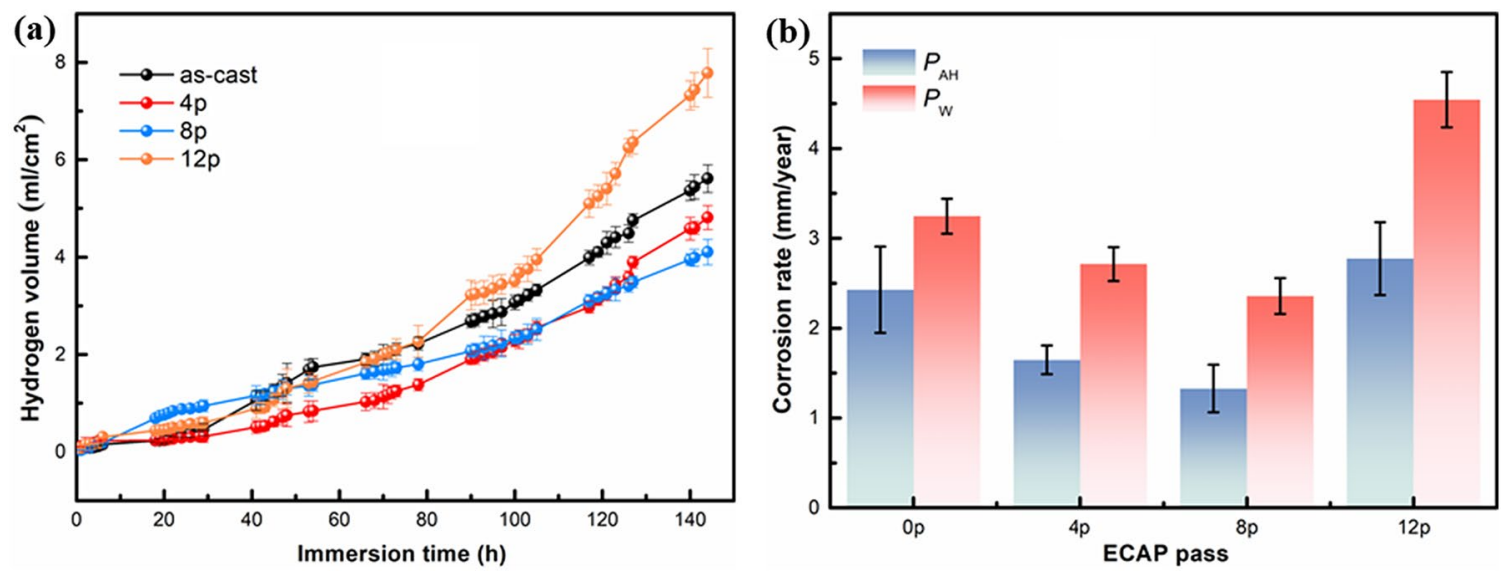

Fig. 5 Hydrogen evolution volume and the corrosion rate of the $\mathrm{Mg}_{98.5} \mathrm{Y}_{1} \mathrm{Zn}_{0.5}$ alloys in as-cast and ECAP conditions after immersed in $37{ }^{\circ} \mathrm{C}$ SBF for $144 \mathrm{~h}$ : a hydrogen evolution volume and $\mathbf{b}$ corrosion rate 


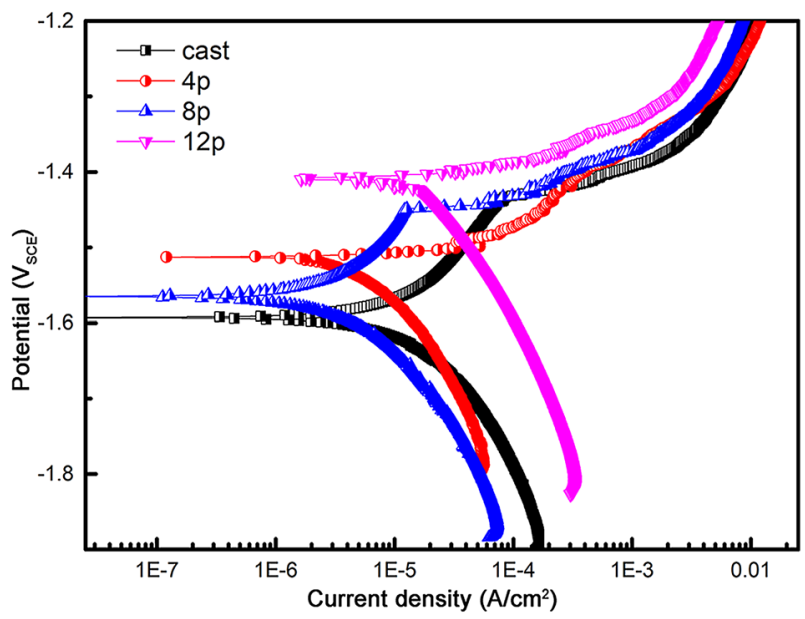

Fig. 6 Potentiodynamic polarization curves of $\mathrm{Mg}_{98.5} \mathrm{Y}_{1} \mathrm{Zn}_{0.5}$ alloys in as-cast and ECAP conditions with surface state containing both coarse grain and very fine grains (Figs. 2d, 3b). Similar phenomenon was reported by Gollapudi et al. who demonstrated that the passive layer was very uniform and compact at some locations while very nonuniform at other sites when they were formed on materials with both coarse and fine grains which were less protective during erosion [49]. The distinct difference of anodic polarization curves between $8 p$ - and $12 p$-processed samples may be related to the distribution of the LPSO particles. Compared with the $8 \mathrm{p}$ sample, the fully broken fined LPSO precipitations in the $12 p$ sample restrained the protective effect of the surface film layer and catalyzed the dissolution of $\mathrm{Mg}$.

\subsection{Corrosion Morphology}

Figure 7 displays the surface morphology of as-cast and ECAP alloys after immersed in $37{ }^{\circ} \mathrm{C} \mathrm{SBF}$ solution for $144 \mathrm{~h}$. These obtained results show that the samples experienced severe erosion after $144 \mathrm{~h}$ immersion. As seen from

Table 2 Electrochemical parameters obtained from potentiodynamic polarization curves

\begin{tabular}{lllllll}
\hline & $E_{\text {corr }}\left(\mathrm{V}_{\mathrm{SCE}}\right)$ & $I_{\text {corr }}\left(\mu \mathrm{A} \mathrm{cm}^{-2}\right)$ & $E_{\mathrm{pit}}\left(\mathrm{V}_{\mathrm{SCE}}\right)$ & $P_{\mathrm{i}}(\mathrm{mm} /$ year $)$ & $P_{\mathrm{AH}}(\mathrm{mm} /$ year $)$ & $P_{\mathrm{W}}(\mathrm{mm} /$ year $)$ \\
\hline as-cast & -1.59 & 21.4 & -1.43 & 0.48 & 2.54 & 3.24 \\
$4 \mathrm{p}$ & -1.512 & 6.2 & - & 0.142 & 1.67 & 2.71 \\
$8 \mathrm{p}$ & -1.56 & 4.16 & -1.44 & 0.095 & 1.43 & 2.35 \\
$12 \mathrm{p}$ & -1.406 & 25.7 & - & 0.58 & 2.71 & 4.54 \\
\hline
\end{tabular}


Fig. 7 SEM observation of as-cast and ECAP $\mathrm{Mg}_{98.5} \mathrm{Y}_{1} \mathrm{Zn}_{0.5}$ alloys after immersed in $37{ }^{\circ} \mathrm{C}$ SBF solution for $144 \mathrm{~h}$ : a as-cast; $\mathbf{b} 4 \mathrm{p} \mathrm{ECAP}$; $\mathbf{c} 8 \mathrm{p}$ ECAP; and d 12p ECAP 
Fig. 7a, deep corrosion pits were detected on the surface of as-cast samples. Grooves with different scales were formed on $4 p$ ECAP-processed samples, and some areas on the surface of the samples suffered from serious corrosion, leaving large corrosion grooves (Fig. 7b). There were obvious filiform corrosion characteristics in the region from the severe corrosion area to the slight corrosion area. For 8p ECAPprocessed specimens, except for some local areas with deep corrosion pits, the eroded region was mainly composed of some wide and shallow corrosion pits which indicate that the corrosion attack mainly grew along the surface instead of penetrated perpendicularly in the deep metallic substrate (Fig. 7c). The view of the surface morphology evidences the aggressive attack which results in the loss of the integrity of $12 p$ ECAP-processed sample during the long-time immersion and reflects their poor anti-erosion performance.

SEM observation was also employed to reveal the local corrosion site after short immersion time for as-cast and


Fig. 8 SEM observation of selected corrosion regions for ECAPalloys after immersed in $37{ }^{\circ} \mathrm{C}$ SBF solution for 24 h: a $4 p$ ECAP; b $8 p$ ECAP; and $\mathbf{c} 12 \mathrm{p}$ ECAP 
ECAP-processed samples (Fig. 8a-c). After immersion for $24 \mathrm{~h}$, shallow grooves are connected and expanded across the sample surface, and the EDS results (Fig. 8 a(I-II)) reveal that the expansion had no preferential orientations. Figure $8 \mathrm{~b}$ shows the corrosion morphology of 8p ECAP-processed sample. The severe distorted structure can be easily identified after the removal of corrosion products. According to the EDS analyses, the kinked structure has high density of solute atoms, which could be the remained LPSO phase. ECAP introduced sever plastic deformation and magnificent adjustment in the distribution of the second phase inside the material. After 8p ECAP process, most of the initial LPSO phases were highly kinked and began to be broken into small pieces. But some still remained unbroken and highly twisted interwoven with the deformed $\mathrm{Mg}$ matrix during the ECAP process. The potential differences between LPSO structure and the $\mathrm{Mg}$ matrix led to the formation of microgalvanic cell in which LPSO worked as cathodic and Mg as the anodic, resulting in the dissolution of $\mathrm{Mg}$ matrix and the remaining of LPSO structure after immersion in $37^{\circ} \mathrm{C}$ (Fig. 8c) [6, 50-53].

\subsection{Effect of ECAP Process on the Corrosion Responds}

In this paper, the ECAP process was employed in order to modify the microstructure of LPSO containing $\mathrm{Mg}_{98.5} \mathrm{Y}_{1} \mathrm{Zn}_{0.5}$ alloys to explore the relationship between microstructure and corrosion behaviors in the biomedical environment. Based on above results, the corrosion rate was associated with the substantial increases in the ECAP numbers, which may be attributed to the decrease in grain sizes and redistribution of LPSO structures [32, 54]. Figure 9 shows the schematic of the grain and second phase. During the ECAP process, changes take place in the distribution and the morphology of LPSO phase within the Mg matrix in association with the grain refinement. According to previous $\mathrm{OM}$ and SEM observations in Fig. 2a-b, the as-cast alloy contains two main phases: $\alpha-\mathrm{Mg}$ and the LPSO structure which were located along the grain boundaries. ECAP processing modifies this distribution by deforming and breaking down the LPSO phases. After 4 ECAP passes, the LPSO structure became bent and kinked, and local recrystallization occurred near the interface between $\mathrm{Mg}$ matrix and deformed LPSO precipitations where the stress concentrations are accumulated due to the incompatibility of deformation between the two phases. Evidenced from Fig. $2 \mathrm{~d}-\mathrm{f}$ indicated that ECAP increased to $8 p$ enhanced the dynamic recrystallization process. After the 8p ECAP process, DRX grains less than $500 \mathrm{~nm}$ can be detected in the refined structure (Fig. 4c). Besides, the kinked LPSO started to be broken into finer pieces. After the $12 p$ ECAP process, the comminution of the LPSO phase was completed. The broken LPSO particles were distributed uniformly inside the matrix.

ECAP process from $0 p$ to $12 p$ leads to changes in the microstructure of $\mathrm{Mg}_{98.5} \mathrm{Y}_{1} \mathrm{Zn}_{0.5}$ alloys including grain refinement and breakdown of LPSO particle, and each of them plays a unique role during the corrosion process. The variation trend of grain size solely seems to show a significant effect on the corrosion behaviors [10, 32], which can

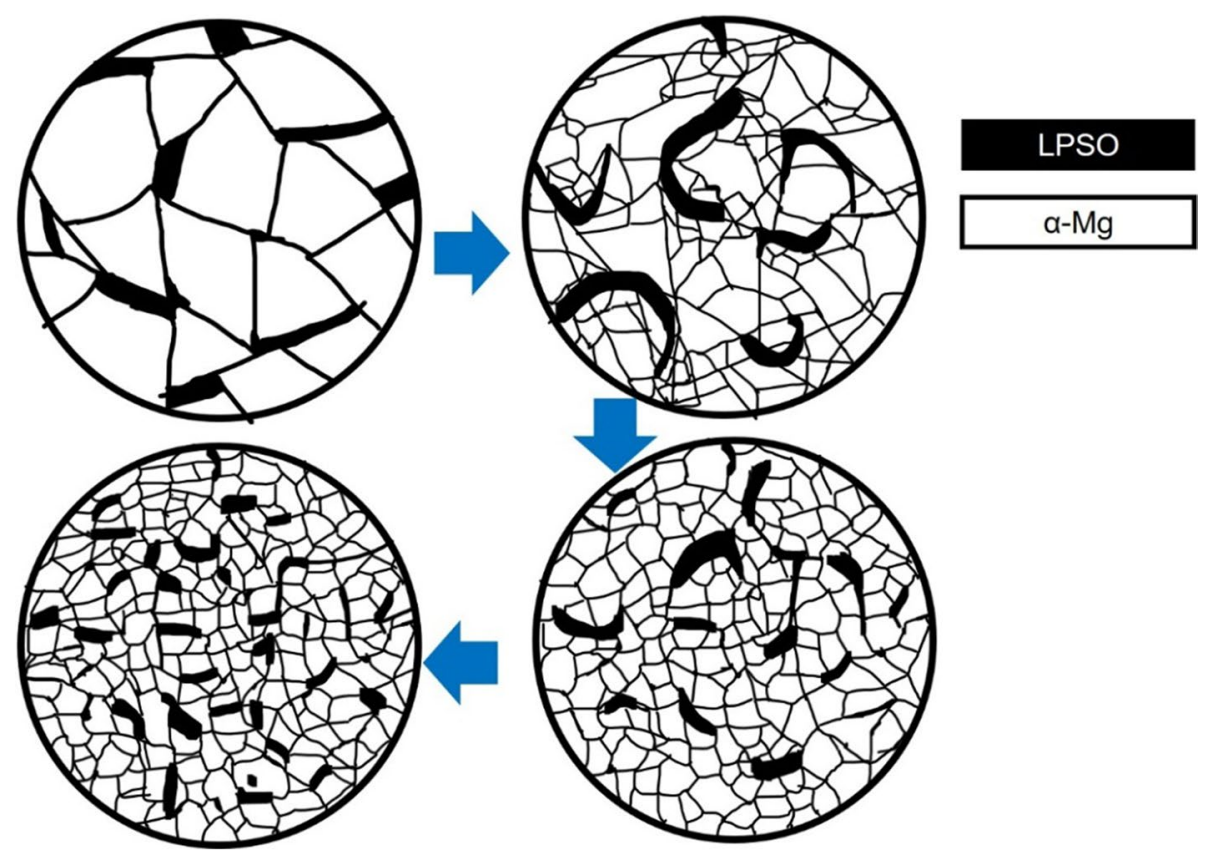

Fig. 9 Schematic of the grain and second particle during the ECAP process from $0 p$ to $12 p$ 
be correlated with the growth of the surface oxide film layer according to the surface condition of the alloys $[55,56]$. It is believed that the surface with high grain boundary density has the ability to passivate more readily, hence increasing the resistance to corrosion properties [23, 57, 58]. Actually, the surface film formed on $\mathrm{Mg}$ surface is partially protective and will lose the integrity when exposed to solutions with the presence of aggressive anions such as chlorides. Liu et al. [59] found that the surface film of $\mathrm{Mg}$ alloys consisted of two noncompact layers: a thin $\mathrm{MgO}$ layer and an external $\mathrm{Mg}(\mathrm{OH})_{2}$ layer. After long immersion, the $\mathrm{MgO}$ layer was replaced by $\mathrm{Mg}(\mathrm{OH})_{2}$ layer. This transformation led to changes in the volume of the film which made cracks occur in the film and then led to the continuous exposure of fresh surface and accelerated further corrosion. Nevertheless, if the $\mathrm{MgO}$ layer is formed on the surface of fine grains, it could cover the material surface more effectively and then reduce the tendency of oxide film damage caused by the subsequent transformation process, thus improving the corrosion resistance of the alloys [55]. The increase in corrosion resistance of the ECAP-processed alloys from $0 p$ to $8 p$ may be originated from the variation in the degree in grain refinement. Compared with the samples after $4 p$ of ECAP, the sample after $8 p$ of ECAP is highly recrystallized. The grain of the $8 \mathrm{p}$ ECAP-processed sample is uniformly refined which makes it easier for the sample to form a more uniform and denser surface film with better protective characteristics.

The changes in morphology and distribution of LPSO structure during the ECAP process also affect the corrosion process. Williams et al. $[60,61]$ employed an in situ scanning vibrating electrode technique to investigate the corrosion behavior of $\mathrm{Mg}$ in a $5 \mathrm{wt} \% \mathrm{NaCl}$ solution. They found that there was enough electron transfer through the $\mathrm{Mg}$ corrosion product layer, and they also detected the cathodic current above the activated surface region. It appears that, during the continued corrosion of $\mathrm{Mg}$, some corroded regions of the $\mathrm{Mg}$ surface are activated, which act as a cathode to intensify further corrosion. Based on the fundamental discoveries of Mcnulty and Hanawalt [62], the activated sites are related to the noble impurity particles [60, 63]. As suggested by Taheri el al [64]. that the corrosion product film formed on the surface of $\mathrm{Mg}$ alloy has enough conductivity, which could effectively transfer the electrons released from the anodic reaction at the $\mathrm{Mg} /$ film interface to the second phase particles at the film/solution interface to support the cathodic reaction. Further consideration may make sense to assume that a poor corrosion resistance with an additional ECAP up to $12 p$ process may result in a redistribution of LPSO structures relating to improved catalytic activity. The fine broken LPSO particles introduced by ECAP process inside the grain could probably activate the local cathodic site and reduce the protective character of the surface films, which leads to the preferential anodic corrosion of $\mathrm{Mg}$ in the second phase. In addition, except for the above factors, ECAP process also leads to changes in microscale which might significantly alter the electrochemical response. Multipass ECAP, especially after 12 p ECAP, can dramatically increase the volume fraction of crystalline defects, such as triple junctions which could be used to reduce atom coordination and increase electronic activity [57]. They might play a role in accelerating the electronic transformation from $\mathrm{Mg} /$ film to the second phase particles and the catalytic cathode activity process, then leading to a significant reduction in the corrosion resistance of the sample after $12 p$ extrusion.

\section{Conclusions}

In this study, the microstructure evolution and corrosion behaviors of a LPSO containing $\mathrm{Mg}_{98.5} \mathrm{Y}_{1} \mathrm{Zn}_{0.5}$ alloy during multi-pass ECAP process were systematically investigated. The following conclusions can be drawn:

1. During multi-pass ECAP, the grains of $\alpha-\mathrm{Mg}$ were refined gradually. The original blocky-shaped $18 \mathrm{R}$ second phases were kinked after $4 \mathrm{p}$ ECAP and then became cracked after 8p ECAP and finally turned into small particles and redistributed within the matrix after $12 p$ ECAP process.

2. The corrosion rates calculated from weight loss of ascast and multi-pass ECAP alloys increased with the following sequence: $8 \mathrm{p}(2.35 \mathrm{~mm} / \mathrm{year})<4 \mathrm{p}(2.71 \mathrm{~mm} /$ year $)<$ as-cast $(3.24 \mathrm{~mm} /$ year $)<12 \mathrm{p}(4.54 \mathrm{~mm} /$ year $)$.

3 . The ECAP process influences the grain size, the morphology, and distribution of LPSO particles through the material and therefore manages the overall corrosion resistance. The improvement in corrosion resistance for $\mathrm{Mg}_{98.5} \mathrm{Y}_{1} \mathrm{Zn}_{0.5}$ alloy from $0 \mathrm{p}$ to $8 \mathrm{p}$ could be ascribed to the refinement of grains, which improved the protection of surface film. The protective effect of the surface film began to lose its dominate control when ECAP process was increased to $12 \mathrm{p}$. The fully broken LPSO precipitations enhanced the cathode catalytic activation of materials and reduce the protective effect of the surface film, thus promoting the rapid dissolution of $\mathrm{Mg}$.

Acknowledgements This work was supported by the National Natural Science Foundation of China (Nos. 51774109, 51979099 and 51901068), the Fundamental Research Funds for the Central Universities (No. 2018B690X14), the Natural Science Foundation of Jiangsu Province of China (No. BK20191303), the Postgraduate Research \& Practice Innovation Program of Jiangsu Province (No. KYCX18_0570), the Key Research and Development Project of Jiangsu Province of China (No.BE2017148), and the Public Service Platform Program of Suqian City of China (No. M201614). 


\section{References}

1. X. Zhang, Q. Wang, F. Chen, Y. Wu, Z. Wang, Q. Wang, Mater. Lett. 212, 138 (2015)

2. L. Bao, Q. Le, Z. Zhang, C. Esling, Mater. Lett. 189, 235 (2019)

3. X. Zong, J. Zhang, W. Liu, Y. Zhang, Z. You, C. Xu, Adv. Eng. Mater. 1800017, 20 (2018)

4. L. Wang, J. Jiang, T. Yuan, Q. Xie, H. Liu, A. Ma, Met. Mater. Int. (2019). https://doi.org/10.1007/s12540-019-00410-3

5. M. Song, R. Zeng, Y. Ding, R.W. Li, M. Easton, I. Cole, N. Birbilis, X. Chen, J. Mater. Sci. Technol. 535, 35 (2019)

6. J. Liu, L. Yang, C. Zhang, B. Zhang, T. Zhang, Y. Li, K. Wu, F. Wang, J. Alloys Compd. 648, 782 (2019)

7. J. Zhang, S. Liu, R. Wu, L. Hou, M. Zhang, J. Magnes. Alloys 277, 6 (2018)

8. K. Hagihara, Z. Li, M. Yamasaki, Y. Kawamura, T. Nakano, Acta Mater. 226, 163 (2019)

9. M. Ullmann, M. Schmidtchen, K. Kittner, T. Henseler, R. Kawalla, U. Prahl, Mater. Sci. Forum 57, 949 (2019)

10. M. El-Tahawy, K. Máthis, G. Garcés, T. Matsumoto, M. Yamasaki, Y. Kawamura, J. Gubicza, J. Alloys Compd. 629, 771 (2019)

11. H. Liu, H. Huang, C. Wang, J. Sun, J. Bai, F. Xue, A. Ma, X. Chen, Jom-Us 3314, 71 (2019)

12. H. Kim, A.J. Ross, S. Shang, Y. Wang, L.J. Kecskes, Z. Liu, Materialia 192, 4 (2018)

13. D. Xu, E. Han, Y. Xu, Prog. Nat. Sci. Mater. Int. 117, 26 (2016)

14. Y. Kawamura, K. Hayashi, A. Inoue, T. Masumoto, Mater. Trans. 1172, 42 (2001)

15. G. Garces, P. Pérez, R. Barea, J. Medina, A. Stark, N. Schell, P. Adeva, Metals 9, 221 (2019)

16. B. Wang, D. Xu, S. Wang, L. Sheng, R. Zeng, E. Han, Int. J. Fatigue 46, 120 (2019)

17. X. Zhang, Y. Wu, Y. Xue, Z. Wang, L. Yang, Mater. Lett. 42, 86 (2012)

18. X. Liu, D. Shan, Y. Song, E. Han, J. Magnes. Alloys 26, 5 (2017)

19. F. Cao, Z. Shi, G. Song, M. Liu, M.S. Dargusch, A. Atrens, Corros. Sci. 176, 90 (2015)

20. Z. Gui, Z. Kang, Y. Li, J. Alloys Compd. 222, 685 (2016)

21. N. Saikrishna, G. Reddy, B. Munirathinam, B. Sunil, J. Magnes. Alloys 68, 4 (2016)

22. H. Wang, Y. Estrin, H. Fu, G. Song, Z. Zúberová, Adv. Eng. Mater. 967, 9 (2007)

23. G.M. Naik, S. Narendranath, S.S.S. Kumar, J. Mater. Eng. Perform. 2610, 28 (2019)

24. M. Gholami-Kermanshahi, V. Neubert, M. Tavakoli, F. Pastorek, B. Smola, V. Neubert, Adv. Eng. Mater. 1800121, 20 (2018)

25. Q. Xu, A. Ma, Y. Li, B. Saleh, Y. Yuan, J. Jiang, C. Ni, Materials 3503, 12 (2019)

26. J. Sun, B. Xu, Z. Yang, H. Zhou, J. Han, Y. Wu, D. Song, Y. Yuan, X. Zhuo, H. Liu, A. Ma, J. Alloys Compd. 152688, 817 (2019)

27. L. Wang, J. Jiang, A. Ma, Y. Li, D. Song, Metals 324, 7 (2017)

28. G. Garces, S. Cabeza, R. Barea, P. Pérez, P. Adeva, Materials (Basel, Switzerland) 733, 11 (2018)

29. H. Liu, H. Huang, X. Yang, C. Li, J. Yan, J. Jiang, A. Ma, J. Magnes. Alloys 231, 5 (2017)

30. Z. Geng, D. Xiao, L. Chen, J. Alloys Compd. 145, 686 (2016)

31. P. Pérez, S. Cabeza, G. Garcés, P. Adeva, Corros. Sci. 107, 107 (2016)
32. M. Esmaily, J. Svensson, S. Fajardo, N. Birbilis, G. Frankel, S. Virtanen, R. Arrabal, S. Thomas, L.G. Johansson, Prog. Mater. Sci. 92, 89 (2017)

33. G. Bi, J. Jiang, F. Zhang, D. Fang, Y. Li, Y. Ma, Y. Hao, J. Rare Earths 931, 34 (2016)

34. C. Li, D. Xu, Z. Zeng, B. Wang, L. Sheng, X. Chen, E.H. Han, Mater. Des. 430, 121 (2017)

35. A. Srinivasan, Y. Huang, C.L. Mendis, C. Blawert, K. Kainer, N. Hort, Mater. Sci. Eng. A 224, 595 (2014)

36. F. Cao, G. Song, A. Atrens, Corros. Sci. 835, 111 (2016)

37. A. Atrens, G. Song, M. Liu, Z. Shi, F. Cao, M. Dargusch, Adv. Eng. Mater. 400, 17 (2015)

38. G. Song, K. Unocic, Corros. Sci. 758, 98 (2015)

39. A. Atrens, G. Song, F. Cao, Z. Shi, P. Bowen, J. Magnes. Alloys 177, 1 (2013)

40. Z. Shi, A. Atrens, Corros. Sci. 226, 53 (2011)

41. K. Hagihara, A. Kinoshita, Y. Sugino, M. Yamasaki, Y. Kawamura, H. Yasuda, Y. Umakoshi, Acta Mater. 6282, 58 (2010)

42. X. Shi, Y. Long, H. Zhang, L. Chen, Y. Zhou, X. Yu, X. Yu, L. Cai, Z. Leng, Materials 498, 12 (2019)

43. G. Song, A. Atrens, Adv. Eng. Mater. 177, 9 (2007)

44. Z. Shi, J. Jia, A. Atrens, Corros. Sci. 296, 60 (2012)

45. G. Song, A. Atrens, D. John, X. Wu, J. Nairn, Corros. Sci. 1981, 39 (1997)

46. S. Lebouil, A. Duboin, F. Monti, P. Tabeling, P. Volovitch, K. Ogle, Electrochim. Acta 176, 124 (2014)

47. G. Frankel, A. Samaniego, N. Birbilis, Corros. Sci. 104, 70 (2013)

48. N. Birbilis, A. King, S. Thomas, G.S. Frankel, J. Scully, Electrochim. Acta 277, 132 (2014)

49. S. Gollapudi, Corros. Sci. 90, 62 (2012)

50. W. Zhou, T. Shen, N. Aung, Corros. Sci. 1035, 52 (2010)

51. J. Liu, L. Yang, C. Zhang, B. Zhang, T. Zhang, Y. Li, K. Wu, F. Wang, J. Mater. Sci. Technol. 1644, 35 (2019)

52. M. Zhao, M. Liu, G. Song, A. Atrens, Corros. Sci. 1939, 50 (2008)

53. Y. Ko, C. Yim, J. Lim, K. Shin, Mater. Sci. Forum 3, 419 (2003)

54. T. Zheng, Y. Hu, S. Yang, J. Magnes. Alloys 404, 5 (2017)

55. D. Orlov, K. Ralston, N. Birbilis, Y. Estrin, Acta Mater. 6176, 59 (2011)

56. H. Torbati-Sarraf, S.A. Torbati-Sarraf, A. Poursaee, T.G. Langdon, Corros. Sci. 90, 154 (2019)

57. K.D. Ralston, N. Birbilis, Corrosion 075005-075005-13, 66 (2010)

58. S.J. Splinter, R. Rofagha, N.S. Mcintyre, U. Erb, Surf. Interface Anal. 181, 24 (1996)

59. M. Liu, S. Zanna, H. Ardelean, I. Frateur, P. Schmutz, G. Song, A. Atrens, P. Marcus, Corros. Sci. 1115, 51 (2009)

60. G. Williams, H. Mcmurray, J. Electrochem. Soc. C340, 155 (2008)

61. G. Williams, N. Birbilis, H. Mcmurray, Electrochem. Commun. 1, $36(2013)$

62. R. Mcnulty, J. Hanawalt, Trans. Electrochem. Soc. 423, 81 (1942)

63. N. Birbilis, G. Williams, K. Gusieva, A. Samaniego, M. Gibson, H. Mcmurray, Electrochem. Commun. 295, 34 (2013)

64. M. Taheri, J. Kish, N. Birbilis, M. Danaie, E. McNally, J. McDermid, Electrochim. Acta 396, 116 (2014) 